\title{
STATUS OF LIPID PEROXIDATION, GLUTATHIONE, ASCORBIC ACID, VITAMIN E AND ANTIOXIDANT ENZYMES IN PATIENTS WITH OSTEOARTHRITIS
}

\author{
KRISHNA MOHAN SURAPANENI, G. VENKATARAMANA
}

\section{ABSTRACT}

BACKGROUND: The exact pro-oxidant and antioxidant status in osteoarthritis patients is still not clear. To add a new insight to the question, changes in the erythrocyte lipid peroxidation products (MDA), levels of glutathione (GSH), ascorbic acid and plasma vitamin $E$ (nonenzymatic antioxidant parameters); and activities of antioxidant enzymes superoxide dismutase $(S O D)$, glutathione peroxidase $\left(G P_{x}\right)$, catalase in erythrocytes and plasma glutathione - $S$ - transferase (GST) were measured in patients with osteoarthritis. AIM: This work was undertaken to assess oxidative stress and antioxidant status in patients with osteoarthritis. SETTINGS AND DESIGN: The study was conducted in 20 patients and compared to controls. Levels of erythrocyte MDA, GSH, ascorbic acid, plasma vitamin $E$; and activities of antioxidant enzymes were measured in patients with osteoarthritis. MATERIALS AND METHODS: Erythrocyte GSH was measured by the method of Beutler et al. Ascorbic acid levels were measured by the method of Tietz. Plasma vitamin E levels were measured by the method of Baker et al. MDA was determined as the measure of thio barbituric acid reactive substances (TBARS). SOD activity in the hemolysate was measured by the method of Misra and Fridovich. Activity of catalase was measured by the method of Beers and Sizer. GP $x$ activity was measured as described by Paglia and Valentine in erythrocytes, and Plasma GST activity was measured as described by Warholm et al. These parameters were measured in 20 patients and compared to controls. STATISTICAL ANALYSIS: Statistical analysis between group 1 (controls) and group 2 (patients) was performed by the student's $t$ test using the stat -view package. RESULTS: It was observed that there was a significant increase in erythrocyte MDA levels; SOD, $G P_{x}$ and plasma GST activities; and a significant decrease in erythrocyte GSH, ascorbic acid, plasma vitamin E levels and catalase activity in patients with osteoarthritis when compared to controls. CONCLUSIONS: The results of our study suggest higher oxygen-free radical production, evidenced by increased MDA and decreased GSH, ascorbic acid, vitamin $E$ and catalase activity, support to the oxidative stress in osteoarthritis. The increased activities of antioxidant enzymes may be a compensatory regulation in response to increased oxidative stress.

Key words: Ascorbic acid, catalase glutathione, glutathione peroxidase, glutathione -s-transferase, malondi aldehyde, osteoarthritis, superoxide dismutase, vitamin $E$ Department of Biochemistry, Dr. Pinnamaneni
Siddhartha Institute of Medical Sciences and Research Foundation, Chinoutpally, Gannavaram, AP, India
Correspondence

Krishna Mohan Surapaneni, Department of Biochemistry, Dr. Pinnamaneni Siddhartha Institute of Medical Sciences and Research Foundation, E-mail: krishnnannavaram - 521 286, A.P., India.
Arthritis, a joint inflammation, refers to a group of diseases that cause pain, swelling, stiffness and loss of motion in the joints. Osteoarthritis is the most common form of arthritis and is a disease of cartilage degeneration. ${ }^{[1]}$ Osteoarthritis, also known as degenerative joint disease, is a process of progressive deterioration of articular cartilage and formation of new bone (osteophyte) at the joint surface. Lipid peroxidation mediated by free radicals is considered to be the major mechanism of cell membrane destruction and cell damage. Free radicals are formed in both physiological and pathological conditions in mammalian tissues. ${ }^{[2]}$ The uncontrolled production of free radicals is considered an important factor in the tissue damage induced by several pathophysiologies. ${ }^{[3,4]}$ Alteration in the oxidant-antioxidant profile is known to occur in rheumatic diseases. ${ }^{[5,6]}$ Oxidative stress due to damage brought about by free radicals is also known to influence the response of these patients to therapy. Moreover, the body's defense mechanisms would play an important role in the form of antioxidants and try to minimize the damage adapting itself to the above stressful situation. Antioxidants are compounds that dispose, scavenge and suppress the formation of free radicals or oppose their actions, ${ }^{[7]}$ and two main categories of antioxidants are those whose role is to prevent the generation of free radicals and those that intercept any free radicals that are generated. ${ }^{[8]}$ They exist in both the aqueous and membrane compartment of cells and can be enzymes or non-enzymes.

In the present study, the following parameters were assessed in erythrocytes and plasma to elucidate the oxidant antioxidant status in patients with osteoarthritis. Erythrocyte MDA levels were measured as TBARS, which serve as an index of the extent of lipid peroxidation. Erythrocyte GSH, ascorbic acid and plasma vitamin $\mathrm{E}$ serve as non-enzymatic antioxidan parameters. The activities of antioxidan enzymes SOD, catalase, $\mathrm{GP}_{x}$ in erythrocytes and GST in plasma were measured. GST is an enzyme involved in antioxidant defense and also in detoxification.

\section{MATERIALS AND METHODS}

The study was conducted in the department of biochemistry, Dr. Pinnamaneni Siddhartha Institute of Medical Sciences and Research Foundation, Chinoutpally, Gannavaram (Mandal), A.P., India. Twenty clinically diagnosed patients with osteoarthritis who had not undergone any previous treatment for their arthritis from orthopedics OPD of $\mathrm{Dr}$. Pinnamaneni Siddhartha Institute of Medical Sciences and Research Foundation Genera Hospital, Chinoutpally, were chosen for the study. An equal number of age- and sexmatched healthy subjects were also investigated. Due permission was obtained from the ethical committee of the Dr. PSIMS and RF General Hospital, Chinoutpally, before the start of the work. Written consents were also taken from the patients prior to study, and the objectives of the study were fully explained. Eight of the participants dropped out at the end of the selection as they did not like the idea of giving blood.

The complete clinical and personal history of the subjects was recorded. The age of the 
subjects was in the range of 35-60 years. All the patients in the study were clinically diagnosed as patients with osteoarthritis. The presence of osteoarthritis in patients was diagnosed by carrying out X-ray analysis of joint destruction, as well as C-reactive protein and antinuclear antibodies test. None of these subjects were alcoholics or chronic smokers, and none of them suffered from any systematic diseases like hypertension or any diabetic complication. Patients suffering from disease of any origin other than osteoarthritis were excluded from the study. Subjects with normal nutritional habits without supplementing with any vitamins during the last 6 months were included. Subjects with history of receiving anti-inflammatory drugs in the last 6 months and history or present symptoms of any other stress-induced disorder were excluded.

There were two study groups. The controls and patients were divided into two groups.

Group 1: Twenty healthy age- and sexmatched controls.

Group 2: Twenty patients with clinically diagnosed osteoarthritis.

The heparinized venous blood samples obtained from these subjects were used for the analysis. Plasma was separated by centrifugation at $1,000 \mathrm{~g}$ for $15 \mathrm{~min}$. Separated plasma was used for the measurement of vitamin E and GST. The buffy coat was removed, and the packed cells were washed three times with physiological saline. The erythrocyte suspension was prepared by the method of Dodge et al., ${ }^{[9]}$ modified by Quist. ${ }^{[10]}$ The packed cells were used for the analysis of GSH, ascorbic acid,
MDA, SOD, catalase, $\mathrm{GP}_{\mathrm{x}}$. Erythrocyte GSH was measured by the method of Beutler et al. ${ }^{[11]}$ using di thio bis nitro benzoic acid (DTNB). Ascorbic acid levels were measured by the method of Tietz. ${ }^{[12]}$ Plasma vitamin $\mathrm{E}$ levels were measured by the method of Baker et al. ${ }^{[13]}$ MDA was determined as the measure of thio barbituric acid reactive substances (TBARS). ${ }^{[14]}$ SOD (EC 1.15.1.1) activity was measured in the hemolysate by the method of Misra and Fridovich ${ }^{[15]}$ based on inhibition of auto-oxidation of epinephrine to adenochrome at $P H$ 10.2. Catalase (EC 1.11.1.6) activity was measured by the method of Beers and Sizer. ${ }^{[16]}$ Activity of $\mathrm{GP}_{x}$ (EC 1.11.1.9) was measured as described by Paglia and Valentine ${ }^{[17]}$ in erythrocytes, and plasma GST (EC 2.5.1.18) activity was measured by using 1-chloro-2, 4-dinitro benzene (CDNB). ${ }^{[18]}$ All reagents used were of analytical reagent grade. DTNB, CDNB and thio barbituric acid were obtained from sigma chemicals, St. Louis, MO.

\section{Statistical analysis}

Statistical analysis between group 1 (controls) and group 2 (patients) was performed by the student's t-test using the stat -view package. The data were expressed as mean \pm SD. $P<0.05$ was considered significant.

\section{RESULTS}

The mean \pm SD of erythrocyte $\mathrm{GSH}$, ascorbic acid, MDA, SOD, catalase, $\mathrm{GP}_{\mathrm{x}}$, plasma vitamin E and GST are reported in Table 1. There was a statistically significant increase in the erythrocyte MDA levels in patients with osteoarthritis compared to controls. The
Table 1: The mean \pm SD values of MDA, GSH, ascorbic acid, vitamin $E, S O D$, catalase, $\mathrm{GP}_{\mathrm{x}}$ and GST in controls and patients with osteoarthritis

\begin{tabular}{|c|c|c|}
\hline Parameter & $\begin{array}{c}\text { Group } 1 \\
\text { (Controls) } n=20\end{array}$ & $\begin{array}{c}\text { Group } 2 \\
\text { (Patients) } n=20\end{array}$ \\
\hline $\begin{array}{l}\text { Glutathione }(\mathrm{mg} / \mathrm{gm} \text { of } \\
\mathrm{Hb})\end{array}$ & $12.69 \pm 0.11$ & $10.90 \pm 0.06^{*}$ \\
\hline Ascorbic acid (mg/dl) & $3.22 \pm 0.14$ & $2.80 \pm 0.12^{\dagger}$ \\
\hline Vitamin E ( $\mu$ moles/liter) & $2.48 \pm 0.10$ & $1.94 \pm 0.05^{*}$ \\
\hline MDA (nmoles/gm of $\mathrm{Hb}$ ) & $3.19 \pm 0.4$ & $6.68 \pm 0.6^{\ddagger}$ \\
\hline $\mathrm{SOD}$ (EU/gm of $\mathrm{Hb})$ & $2289.30 \pm 326.70$ & $3143.87 \pm 319.09^{\dagger}$ \\
\hline $\begin{array}{l}\text { Catalase }\left(\mathrm{nmoleH}_{2} \mathrm{O}_{2}\right. \\
\text { decomposed } / \mathrm{mg} \\
\text { protein } / 1 \mathrm{~min})\end{array}$ & $2.62 \pm 0.28$ & $1.43 \pm 0.07^{\dagger}$ \\
\hline $\mathrm{GP}_{\mathrm{x}}(\mathrm{u} / \mathrm{gm}$ of $\mathrm{Hb})$ & $48.95 \pm 2.27$ & $69.45 \pm 4.13^{\ddagger}$ \\
\hline $\begin{array}{l}\text { GST (micromoles/ } \\
\text { dl of plasma) }\end{array}$ & $6.91 \pm 0.4$ & $10.89 \pm 0.12^{\dagger}$ \\
\hline
\end{tabular}

controls, $¥ P<0.01$ compared to controls

activities of erythrocyte antioxidant enzymes SOD, $\mathrm{GP}_{\mathrm{x}}$ and plasma GST were significantly increased in group 2 compared to group 1. The levels of erythrocyte $\mathrm{GSH}$, ascorbic acid, plasma vitamin $\mathrm{E}$ and catalase activity were significantly decreased in patients with osteoarthritis compared to controls.

\section{DISCUSSION}

In the present study, the lipid peroxidation product, i.e., MDA levels, has increased significantly in erythrocytes of patients with osteoarthritis. Rise in MDA could be due to increased generation of reactive oxygen species (ROS) due to the excessive oxidative damage generated in these patients. These oxygen species in turn can oxidize many other important biomolecules, including membrane lipids. Similar results of elevated MDA levels have been reported in patients with rheumatic disease. ${ }^{[5]}$

We observed a significant decrease in the levels of erythrocyte GSH, ascorbic acid and plasma vitamin $\mathrm{E}$ (non-enzymatic antioxidant defense system) in patients with osteoarthritis when compared to controls. The decrease in the levels of these nonenzymatic antioxidant parameters may be due to the increased turnover for preventing oxidative damage in these patients suggesting an increased defense agains oxidant damage in osteoarthritis. Similar results of decreased vitamin $\mathrm{E}$ levels were reported by Scherak et al.. ${ }^{[19]}$

In our study, the erythrocyte antioxidant

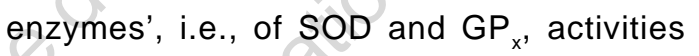
have been increased significantly in patients with osteoarthritis. Similar results of raised SOD and $\mathrm{GP}_{\mathrm{x}}$ activities have been reported in patients with rheumatic diseases. ${ }^{[5,6]}$ SOD is an important antioxidant enzyme having an antitoxic effect against superoxide anion. The over-expression of SOD might be an adaptive response, and it results in increased dismutation of superoxide to hydrogen peroxide. $\mathrm{GP}_{\mathrm{x}}$, an oxidative stress inducible enzyme, plays a significant role in the peroxyl-scavenging mechanism and in maintaining functional integration of the cell membranes. ${ }^{[20]}$ The rise in the levels of GP could be due to its induction to counter the effect of increased oxidative stress Ostalowska et al. have reported increased activities of SOD, glutathione peroxidase and glutathione reductase in synovial fluid of patients with primary and secondary osteoarthritis of the knee joint. ${ }^{[6]}$

The glutathione - $S$ - transferases are a group of multifunctional proteins which play a central role in detoxification of electrophilic chemicals and the hepatic removal of 
potentially harmful hydrophobic compounds from blood. ${ }^{\left[{ }^{21]}\right.}$ We have observed a significant increase in the levels of GST patients with osteoarthritis compared to controls. Similar reports of raised GST levels were observed. ${ }^{[6]}$ The rise in the levels of GST could be due to its induction to counter the effect of increased oxidative stress.

\section{CONCLUSION}

In the present study, we have observed a significant decrease in the activity of catalase in patients with osteoarthritis compared to controls. Catalase is an enzyme which protects the cells from accumulation of hydrogen peroxide by dismutating it to form water and oxygen or by using it as an oxidant, in which it works as a peroxidase. ${ }^{\text {[2] }}$ In conclusion, oxidative stress may be involved in osteoarthritis. The results of our study suggest higher oxygen-free radical production and decreased catalase activity, supporting the higher oxidative stress hypothesis in osteoarthritis. The increased activities of antioxidant enzymes may be a compensatory regulation in response to increased oxidative stress. The results suggest the necessity for therapeutic coadministration of antioxidants with conventional drugs to such patients. Therefore, treatment with antioxidants in the initial stages of the disease may be useful as secondary therapy to prevent the oxidative damage and deterioration of the musculoskeletal tissues in osteoarthritis. The findings implicate oxidative stress in the disease and cite the biochemical rationale for clinical trials of antioxidants to prevent and treat osteoarthritis. However, due to the limited number of cases included in this study, more studies may be required to substantiate the results and arrive at a definite conclusion in terms of safety and efficacy of adding antioxidant therapy as secondary therapy for the treatment of osteoarthritis.

\section{REFERENCES}$$
\text { No }
$$

1. Poole AR. An introduction to the pathophysiology of osteoarthritis. Front Biosci 1999;4:D662-70.

2. Plaa GL, Witschi H. Chemicals, drugs and lipid peroxidation. Ann Rev Pharmacol Toxicol 1976;16:125-41.

3. Mapp PI, Grootveld MC, Blake DR. Hypoxia, oxidative stress and rheumatoid arthritis. $\mathrm{Br}$ Med Bull 1995;51:419-36.

4. Sato M, Miyazaki T, Nagaya T, Murata $\mathrm{Y}$, Ida N, Maeda K, et al. Antioxidants inhibit tumor necrosis factor-alpha mediated stimulation of interleukin-8, monocyte chemo attractant protein-1 and collagenase expression in cultured human synovial cells. J Rheumatol 1996;23:432-8.

5. Mezes M, Bartosiewicz G. Investigations on vitamin $E$ and lipid peroxide status in rheumatic diseases. Clin Rheumatol 1983;2:259-63.

6. Ostalowska A, Birkner E, Wiecha M, Kasperczyk $\mathrm{S}$, Kasperczyk A, Kapolka D, et al. Lipid peroxidation and antioxidant enzymes in synovial fluid of patients with primary and secondary osteoarthritis of the knee joint. Osteoarthritis Cartilage 2006;14:139-45.

7. Sie H. Oxidative stress: From basic research to clinical application. Am J Med 1991;91:31S-8.

8. Cotgreave IA, Moldeus P, Orrenius S. Host biochemical defense mechanisms against prooxidants. Annu Rev Pharmacol Toxicol 1988;28:189-212.

9. Dodge JF, Mitchell G, Hanahan DJ. The preparation and chemical characterization of hemoglobin free ghosts of human red blood cells.
Arch Biochem Biophys 1968;110:119-30.

10. Quist EE. Regulation of erythrocyte membrane shape by calcium ion. Biochem Biophys Res Commun 1980;92:631-7.

11. Beutler E, Duron O, Kelly BM. Improved method for the determination of blood glutathione. J Lab Clin Med 1963;61:882-8.

12. Tietz NW. In: Text book of clinical chemistry. Tietz NW, editor. WB Saunders Company: Philadelphia, London, Toronto; 1986. p. 960-2.

13. Baker H, Frank D, Winley NC. Clini Vitaminol 1968;772.

14. Jain SK, Mcvie R, Duett J, Herbst JJ. Erythrocyte membrane lipid peroxidation and glycosylated hemoglobin in diabetes. Diabetes 1989;38:1539-43.

15. Misra HP, Fridovich I. The role of super oxide anion in the auto oxidation of epinephrine and a simple assay for super oxide dismutase. J Biol Chem 1972;247:3170-5.

16. Beers RF Jr, Sizer IW. A spectrophotometric method for measuring the breakdown of hydrogen peroxide by catalase. J Biol Chem 1952;195:133-40.

17. Paglia DE, Valentine WN. Studies on the quantitative and qualitative characterization of erythrocyte glutathione peroxidase. J Lab Clin Med 1967;70:158-69.

18. Warholm M, Guthenberg C, Christer von Bahr, Mannervik B. Glutathione transferases from human liver. In: Methods of enzymolog. Melster A, editor. Academic Press: 1985. p. 500-1.

19. Scherak O, Kolarz G, Schodl C, Blankenhorn G. High dosage vitamin $E$ therapy in patients with activated arthrosis. J Rheumatol 1990;49:369-73.

20. Chandra R, Aneja R, Rewal C, Konduri R, Dass K, Agarwal S. An opium alkaloid-papaverine ameliorates ethanol induced hepatotoxicity: Diminution of oxidative stress. Indian J Clin Biochem 2000;15:155-60.

21. Smith GJ, Ohl VS, Litwack G. Ligandin, the glutathione S-transferases, and chemically induced hepatocarcinogenesis: A review. Cancer Res 1977;37:8-14.

22. Lenzi A, Culasso F, Gandini L, Lombardo F Dondero F. Placebo-controlled, double-blind, crossover trial of glutathione therapy in male infertility.
Indian J Med Sci, Vol. 61, No. 1, January 2007 